\title{
A controlled study of bone mineral density in patients with inflammatory bowel disease
}

\author{
J A Silvennoinen, T J Karttunen, S E Niemelä, J J Manelius, J K Lehtola
}

\begin{abstract}
To assess the prevalence of and risk factors for low bone mineral density in inflammatory bowel disease (IBD), 152 IBD patients and 73 healthy controls were studied. Sixty seven patients had ulcerative colitis, 78 had Crohn's disease (52 of them (66.7\%) had ileal disease), and seven had indeterminate colitis. Bone mineral density values $\left(\mathrm{g} / \mathrm{cm}^{2}\right)$ measured by dual energy $x$ ray absorbtiometry at the spine (L2-L4), the femoral neck, Ward's triangle, and the trochanter were $1 \cdot 177,0 \cdot 948,0 \cdot 850$, and 0.838 in the patients and $1.228(p=0.034)$, $1.001(p=0.009), 0.889$ (NS), and 0.888 $(p=0.012)$ in the control group, respectively. The type or extent of the disease or previous small bowel resection did not have any significant effect on the bone mineral density values. There was a weak, but statistically significant negative correlation between bone mineral density and the total lifetime corticosteroid dose (in the lumbar spine $r=-0.164, p=0.04$, the femoral neck $r=-0.185, p=0.02$, Ward's triangle $r=-0 \cdot 167, p=0 \cdot 04$, and the trochanter $r=-0.237, p=0.003)$. The patients whose lifetime corticosteroid dose (prednisone/ prednisolone) was more than $10 \mathrm{~g}$ had especially low bone mineral density ( $p<0.05$ compared with the groups with no or less than $5 \mathrm{~g}$ of corticosteroid). The patients who had never taken peroral corticosteroids did not have decreased bone mineral density. In conclusion, IBD patients have significantly lower bone mineral density values than healthy controls, but the difference is not so great as has been reported previously. Low bone mineral density values in these patients are related to high lifetime corticosteroid doses.
\end{abstract}

(Gut 1995; 37: 71-76)

Keywords: bone mineral density, inflammatory bowel disease, Crohn's disease, colitis ulcerosa, osteoporosis, corticosteroid treatment.

In patients with inflammatory bowel disease (IBD), disease activity, corticosteroid treatment, and nutritional status may all have harmful effects on the bone. A decreased bone mineral content and decreased bone mineral density and even severe clinical osteoporosis resulting in stress fractures have been seen in patients with small or large intestinal IBD, or both. ${ }^{1-3}$ Increased rates of both spinal and cortical bone loss have also been reported in patients with IBD. ${ }^{45}$ In a follow up study of children with IBD, osteoporosis was one of the most common complications. ${ }^{6}$ The possible pathogenic factors in this patient group include corticosteroid treatment, ${ }^{7}$ calcium malabsorption, sex hormone deficiency, and vitamin D deficiency. ${ }^{8-10}$ However, the precise pathogenic mechanisms are still unclear. ${ }^{4}$

The prevalence of low bone mineral density obviously depends on patient selection. In some studies, as many as $23-31 \%$ of the IBD patients had bone mineral density values more than two standard deviations (SD) below the previously published normal values, ${ }^{12}$ but these studies included a great number of patients with intestinal resections. In a Danish study, $45 \%$ of patients with Crohn's disease were without clinical symptoms during a median follow up time of $5 \cdot 5$ years and $45 \%$ of the patients had not been treated surgically after a follow up of 10 years. ${ }^{11}$ It is therefore important to include even the mild cases of IBD in investigations of bone mineral density in these patients. In this study, we investigated the prevalence and severity of osteoporosis in IBD patients with a controlled prospective design by measuring the bone mineral density of 152 IBD patients selected randomly from the patient register and 73 healthy controls. A special effort was made to achieve an accurate diagnosis of IBD and to study corticosteroid use.

\section{Methods}

\section{Patients and controls}

The patients were selected from the IBD register of the gastroenterology unit at the Department of Internal Medicine, University Hospital of Oulu, Oulu, Finland. All the IBD patients treated in this hospital since 1986 have been entered in the register. The patients, whose diagnosis was made later than 1990 or who had IBD limited to the rectum only were excluded. Patients within the age range of 19-60 years were included in the study population. At the end of the year 1992, the register contained 248 ulcerative colitis patients and 90 patients with Crohn's disease who fulfilled the study criteria. Ninety of 248 ulcerative colitis patients were randomly selected using random numbers and version 2.1 of the statistical software program Medstat. These 90 ulcerative colitis patients together with all the 90 Crohn's disease patients fulfilling the study criteria were invited to participate. Two pregnant women were excluded because of the radiation dose needed for densitometry. Eighty one patients with an earlier diagnosis of Crohn's disease 
TABLE I Baseline characteristics of the patients and the controls

\begin{tabular}{lcccc}
\hline & Controls & $\begin{array}{l}\text { Ulcerative } \\
\text { colitis }\end{array}$ & $\begin{array}{l}\text { Crohn's } \\
\text { disease }\end{array}$ & $\begin{array}{l}\text { Indeterminate } \\
\text { colitis }\end{array}$ \\
\hline Number & $73^{\star}$ & 67 & 78 & 7 \\
Age (y) & $40 \cdot 8(9 \cdot 3)$ & $42 \cdot 0(9 \cdot 6)$ & $38 \cdot 6(8 \cdot 7)$ & $35 \cdot 6(9 \cdot 7)$ \\
Height (cm) & $169 \cdot 0(8 \cdot 1)$ & $168 \cdot 1(9 \cdot 8)$ & $170 \cdot 1(10 \cdot 2)$ & $174 \cdot 7(5 \cdot 9)$ \\
Weight (kg) & $72 \cdot 8(12 \cdot 6)$ & $69 \cdot 0(13 \cdot 4)$ & $70 \cdot 0(13 \cdot 8)$ & $74 \cdot 1(11 \cdot 9)$ \\
Body mass index (kg/m $\left.{ }^{2}\right)$ & $25 \cdot 5(3 \cdot 8)$ & $24 \cdot 3(3 \cdot 8)$ & $24 \cdot 1(4 \cdot 0)$ & $24 \cdot 3(3 \cdot 9)$ \\
Men/women & $35 / 38$ & $35 / 32$ & $41 / 37$ & $4 / 3$ \\
Calcium supplementation (n) (\%) & $10(13 \cdot 7)$ & $11(16 \cdot 4)$ & $17(21 \cdot 8)$ & $0(0)$ \\
Vitamin D supplementation (n) (\%) & $12(16 \cdot 4)$ & $15(22 \cdot 4)$ & $23(29 \cdot 5)$ & $2(28 \cdot 6)$ \\
Postmenopausal women (n) (\%) & $7(9 \cdot 6)$ & $9(13 \cdot 4)$ & $5(6 \cdot 4)$ & $0(0)$ \\
Age at menarche (y) & $12 \cdot 8(1 \cdot 3) \dagger$ & $13 \cdot 8(1 \cdot 6) \dagger$ & $13 \cdot 1(1 \cdot 7)$ & $14 \cdot 0(0 \cdot 0)$ \\
& & & & \\
\hline
\end{tabular}

‡The values given are either the number of subjects with the characteristic or the mean (SD or the percentage of the group). $t p<0.05$ between the groups. No other statistical differences between the groups was found. (Statistical significance between multiple groups was determined by an analysis of variance followed by the Student-Newman-Kuels test and $\chi^{2}$ statistics for the comparison of incidences. A p value less than 0.05 was considered significant.)

and 74 patients with an earlier diagnosis of ulcerative colitis agreed to participate $(86 \%$ of the initially randomised group).

All the available histological specimens were re-evaluated by one pathologist (TK). The histological diagnosis was made in each case according to the criteria described by Chong et $a l .{ }^{12}$ The extent of IBD was evaluated from the histological specimens. On the basis of endoscopies, histological findings, possible operative findings, and other patient data, two gastroenterologists re-evaluated the diagnoses according to the criteria previously described by Pera et al..$^{13}$ After a re-classification of some patients, the final diagnoses were ulcerative colitis in 67 patients, Crohn's disease in 78, and indeterminate colitis in seven patients. Three patients did not fulfil the criteria for IBD (one radiation colitis, one solitary rectal ulcer, one histologically 'normal' colon) and were therefore excluded. Seventy three healthy controls with the same age and sex distribution as the patient group were selected from the staff of the Finnish State Railways in Oulu. Their medical records in the occupational health service were studied. Both the patients and the controls represented several different occupational groups from manual workers to office personnel.

Patient data concerning subjective symptoms and the menstrual history in women were collected in personal interviews. The data concerning treatment and the course of IBD were collected from the patient documents. Previous corticosteroid treatment and the possible history of fractures were checked from the hospital records and in the patient interviews. The corticosteroid dose was expressed in grams of prednisone/prednisolone. To

TABLE II Bone mineral densities (BMD, $\mathrm{g} / \mathrm{cm}^{2}$ ) and $Z$ scores (based on the age and sex adjusted control values previously published by Kröger et $\mathrm{al}^{14}{ }^{15}$ ) of the patient and control groups

\begin{tabular}{|c|c|c|c|c|}
\hline & Patients $(n=152)$ & Controls $(n=73)$ & $C L$ for difference ${ }^{\star}$ & Significance \\
\hline \multicolumn{5}{|l|}{ BMD } \\
\hline lumbar spine & $1 \cdot 177(0 \cdot 173)$ & $1 \cdot 228(0 \cdot 156)$ & 0.004 to 0.098 & $p=0.034$ \\
\hline Femoral neck & $0.948(0.143)$ & $1.001(0.139)$ & 0.014 to 0.093 & $\mathrm{p}=0.009$ \\
\hline Ward's triangle & $0.850(0.160)$ & $0.889(0.162)$ & -0.006 to 0.084 & NS \\
\hline Trochanter & $0.838(0.142)$ & $0.888(0 \cdot 126)$ & 0.011 to 0.088 & $\mathrm{p}=0.012$ \\
\hline \multicolumn{5}{|l|}{$Z$ score } \\
\hline Lumbar spine & $-0.028(1.332)$ & $0 \cdot 400(1 \cdot 182)$ & 0.067 to 0.788 & $\mathrm{p}=0.020$ \\
\hline Femoral neck & $-0.364(1.195)$ & $0.122(1.097)$ & 0.159 to 0.813 & $\mathrm{p}=0.004$ \\
\hline Ward's triangle & $-0.128(1.188)$ & $0.194(1.103)$ & -0.003 to 0.649 & $\mathrm{p}=0.05$ \\
\hline Trochanter & $-0.185(1.196)$ & $0.291(1.003)$ & 0.157 to 0.796 & $\mathrm{p}=0.004$ \\
\hline
\end{tabular}

${ }^{\star} 95 \%$ confidence limits for the mean difference. + Student's unpaired $t$ test $(N S=p>0.05)$. Data presented as mean (SD). minimise seasonal variation, all the interviews and bone mineral density measurements were performed in April and May 1993.

\section{Bone mineral density}

The bone mineral density measurements were made by one trained person using dual energy $x$ ray absorptiometry (Lunar DPX, the Lunar software version 3.1, Lunar Radiation Corporation, Madison, WI). The measurement sites were the lumbar vertebrae L2-L4 in the spine, the femoral neck, Ward's triangle, and the trochanter in the left proximal femur. The precision of the method (coefficient of variation) was determined by examining 19 persons twice with an interval of a couple of minutes between the measurements. For bone mineral density in the spine, the femoral neck, Ward's triangle, and the trochanter the coefficient of variation was $1.38 \%, 1.61 \%, 3.60 \%$, and $1.59 \%$, respectively. The bone mineral density values of the patients were compared both with the bone mineral density values of the control subjects and with previously published Finnish normal values. ${ }^{1415}$ For each person, the values of bone mineral density were also expressed as a fraction of the SD of the mean of the previously published normal value for the patient's sex and decade of age ( $Z$ score).

\section{Statistics}

The results are presented as mean (SD). Student's unpaired $t$ test was used when appropriate. When the variances were unequal or the distribution was not normal, the MannWhitney $U$ test was used. An analysis of variance followed by the Student-NewmanKeuls test was used to assess the differences between multiple groups. A comparison of incidences was performed using $\chi^{2}$ statistics or Fisher's exact test. Pearson's correlation coefficients were calculated for the continuous variables. Two tailed values for significance were used in all the statistical tests and significance was defined as $p<0.05$. The analyses were made with the Statistical Package for Social Sciences (SPSS).

The study was approved by the ethics committee of the University Hospital of Oulu. An informed consent was obtained from all the patients and controls before the examination.

\section{Results}

Table I gives the basic characteristics of the population studied. At the time of the study, the patients had had symptoms of IBD for $13 \cdot 1$ $(6 \cdot 2)$ (mean (SD)) (range 5-32) years and the time since the diagnosis of IBD was $11.5(6.0)$ (3-32) years. Forty two of $67(62 \cdot 7 \%)$ patients with ulcerative colitis and 45 of $78(57 \cdot 7 \%)$ with Crohn's disease received sulphasalazine or 5-aminosalicylic acid treatment at the time of the study. Four of the ulcerative colitis patients and seven patients with Crohn's disease had had immunosuppressive treatment (mainly atzathioprine). Extraintestinal manifestations of IBD had been diagnosed in 37 of 


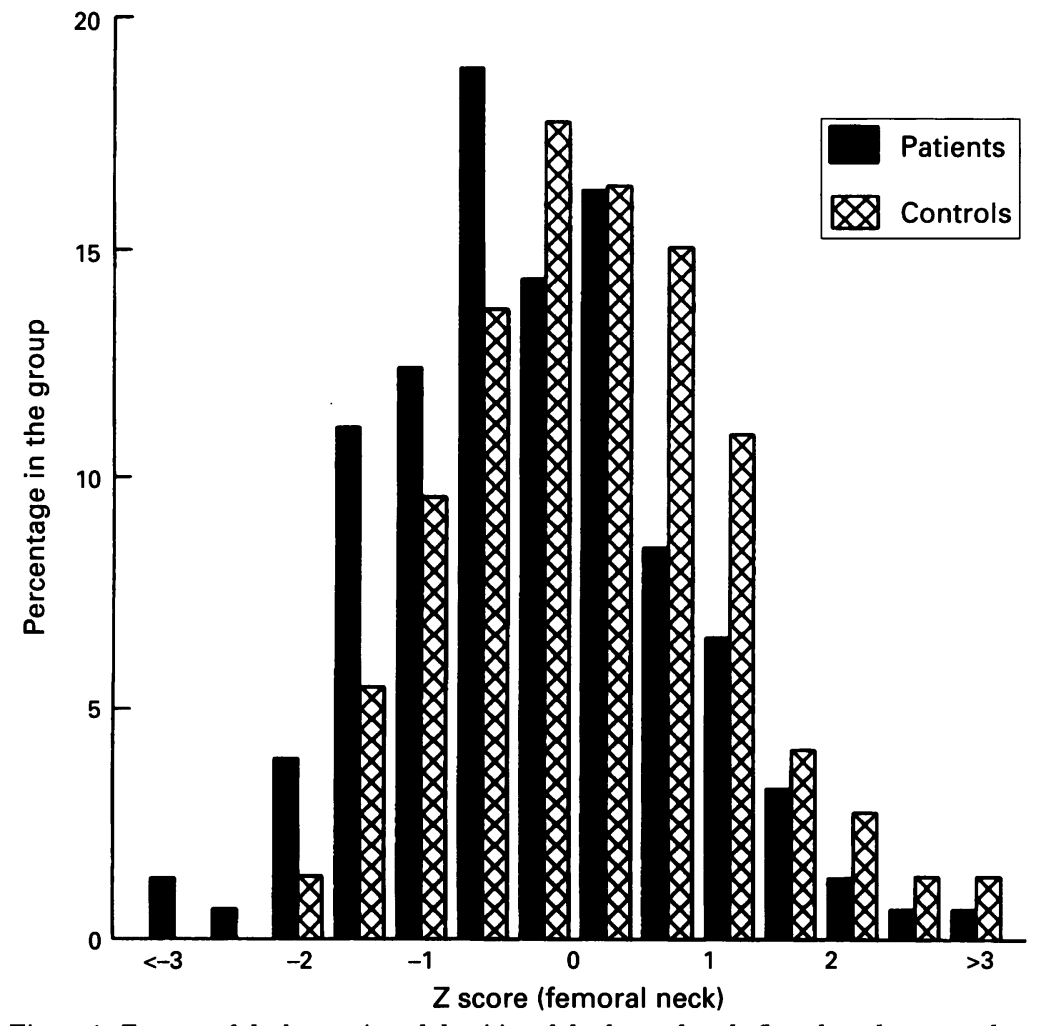

Figure 1: $Z$ scores of the bone mineral densities of the femoral neck (based on the age and sex adjusted control values previously published by Kröger et $\mathrm{al}^{14}{ }^{15}$ ) in 152 patients with inflammatory bowel disease and 73 healthy controls.

$152(24 \cdot 3 \%)$ patients. Operations had been performed on 152 patients: $12(7 \cdot 9 \%)$ patients had had colectomy (seven with ulcerative colitis, four with Crohn's disease, and one with indeterminate colitis), four $(2 \cdot 6 \%)$ had had colonic resection (one with ulcerative colitis and three with Crohn's disease), seven (4.6\%) had had ileocaecal resection, and $10(6.6 \%)$ had had some other small bowel resection. All the patients with small bowel resection had Crohn's disease.

Table II shows the bone mineral density values and $Z$ scores of the control and patient groups. Figure 1 shows the $\mathrm{Z}$ score distribution in the femoral neck. Body mass index had a significant correlation with bone mineral density at all sites in both the patients and the controls. Seventy five $(49.3 \%)$ of the patients and $23(31 \cdot 5 \%)$ of the controls had a 'normal' body mass index of $19-24 \mathrm{~kg} / \mathrm{m}^{2}$. In the femoral neck the bone mineral density of these subjects was $0.902(0.132) \mathrm{g} / \mathrm{cm}^{2}$ in the patient group and $0.948(0.121) \mathrm{g} / \mathrm{cm}^{2}$ in the controls (NS).

TABLE III Bone mineral density (BMD, $\mathrm{g} / \mathrm{cm}^{2}$ ) and $Z$ scores (based on the age and sex adjusted control values previously published by Kröger et $\mathrm{al}^{14}{ }^{15}$ ) in the different types of inflammatory bowel disease

\begin{tabular}{|c|c|c|c|}
\hline & $\begin{array}{l}\text { Ulcerative colitis } \\
(n=67)\end{array}$ & $\begin{array}{l}\text { Crohn's disease } \\
(n=78)\end{array}$ & $\begin{array}{l}\text { Indeterminate colitis } \\
(n=7)\end{array}$ \\
\hline \multicolumn{4}{|l|}{ BMD } \\
\hline Lumbar spine & $1 \cdot 178(0 \cdot 194)$ & $1 \cdot 164(0 \cdot 146)$ & $1.312(0.203)$ \\
\hline Femoral neck & $0.941(0.152)$ & $0.944(0.132)$ & $1.057(0.166)^{\star}$ \\
\hline Ward's triangle & $0.838(0.172)$ & $0.850(0.146)$ & $0.967(0.166)$ \\
\hline Trochanter & $0.839(0 \cdot 148)$ & $0 \cdot 831(0 \cdot 135)$ & $0.918(0.174)$ \\
\hline \multicolumn{4}{|l|}{ Z score } \\
\hline Lumbar spine & $0.363(1.461)$ & $-0 \cdot 180(1 \cdot 146)$ & $1.061(1.596)^{\star}$ \\
\hline Femoral neck & $-0.380(1.298)$ & $-0.425(1.092)$ & $0.474(1 \cdot 104)$ \\
\hline Ward's triangle & $-0.126(1.296)$ & $-0 \cdot 190(1 \cdot 109)$ & $0.533(0.833)$ \\
\hline Trochanter & $-0.176(1.278)$ & $-0 \cdot 248(1 \cdot 121)$ & $0.421(1 \cdot 196)$ \\
\hline
\end{tabular}

${ }^{\star} p<0.05$ compared with patients with Crohn's disease (analysis of variance followed by the Student-Newman-Keuls test). Data presented as mean (SD).
Fourteen $(9 \cdot 2 \%)$ of 152 patients had been under 18 years of age when their IBD had been discovered. The bone mineral density or the $Z$ score values of these patients were not statistically different from those who had been diagnosed at adult age.

In women, there were no differences in the number of pregnancies or the use of oestrogen treatment between the patients and the controls. Five of 72 women $(6.9 \%)$ in the patient group and seven of $38(18.4 \%)$ in the control group had been using oestrogen treatment (for purposes other than contraception). Their age and sex adjusted bone mineral density values were not significantly different from the others. Twelve $(16.7 \%)$ of 72 women patients and two $(5.3 \%)$ of 38 women controls had had amenorrhoea, but they did not have different $Z$ scores of bone mineral density in either of the groups when compared with the women who had normal menstrual history. The medical documents showed none of the patients or controls to have a history of osteoporotic or other pathological fractures, but as $x$ rays were not taken, spinal fractures could not be excluded.

\section{Effect of operations and the type of IBD on bone} mineral density

The patients with previous colectomy $(n=12)$ had lower bone mineral density values than the patients who had not had small bowel resection or colectomy $(n=123)$, but the differences were not statistically significant. The mean length of the small bowel resection was $40 \cdot 0$ $(28 \cdot 2)(10-100) \mathrm{cm}$ and the time since the resection $8.6(6.4)(2-20)$ years. The bone mineral density did not correlate with the time that had passed since the small bowel resection.

When the patients with different types of IBD were compared, no significant differences in bone mineral density or $\mathrm{Z}$ scores between the patients with ulcerative colitis and Crohn's disease were found (Table III). There was no significant difference in bone mineral density at any site between the patients with ileal inflammation in the histological specimens $(n=56)$ and the patients without ileitis $(n=96)$. On the basis of the histological specimens, 25 $(37.3 \%)$ of the ulcerative colitis patients had left sided colitis. The bone mineral density of these patients was not different from that of the ulcerative colitis patients with total colitis. The duration of the disease did not correlate with bone mineral density at any site measured (Fig 2).

Twenty of the 152 patients $(13 \cdot 2 \%)$ had another disease apart from IBD that might affect bone: two had kidney disease, seven ankylosing spondylitis, two coeliac disease, six liver disease, one had been operated on because of a mild hyperparathyreosis, one was investigated because of a suspicion of a mild hyperparathyreosis, and one had had hyperthyreosis. The bone mineral density values of these patients, however, were not significantly different from those of the other patients. At the time of the clinical examination, two patients of $152(1.3 \%)$ had diarrhoea or blood 


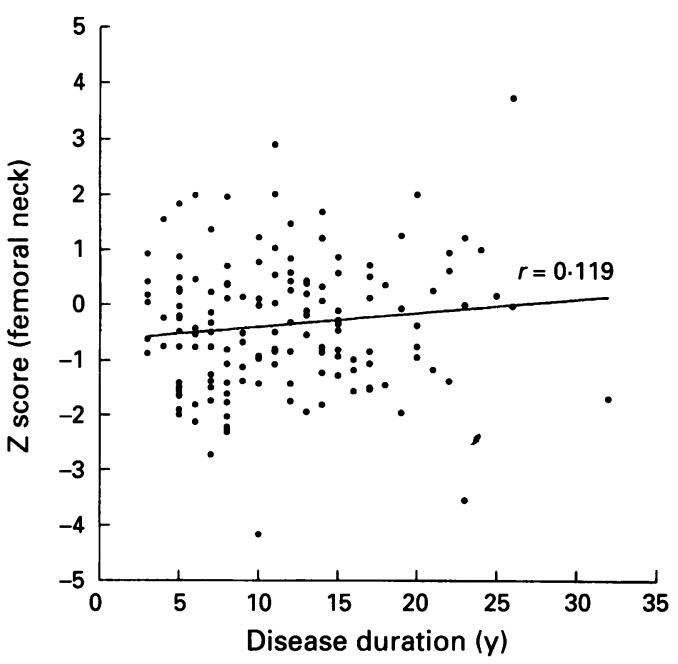

Figure 2: Correlation of the duration of the disease (time since the diagnosis was established) and the $Z$ score of the bone mineral density in the femoral neck in 152 patients with inflammatory bowel disease.

in stools on a daily basis and fever or other generalised symptoms, $22(14.5 \%)$ had diarrhoea or blood in stools every day, but no generalised symptoms, $33(21.7 \%)$ had only mild symptoms less often than daily, and $95(62.5 \%)$ had no symptoms related to IBD. When the patients with mild or no symptoms $(n=128)$ were compared with the patients with a more symptomatic disease $(n=24)$, no significant differences in bone mineral density at any site were found (in the femoral neck the mean difference was $0.014 \mathrm{~g} / \mathrm{cm}^{2}$ ).

\section{Bone mineral density in patients with different medical treatment}

Of the 152 patients, $110(72 \cdot 4 \%)$ had used peroral corticosteroids. The mean duration of corticosteroid treatment was $17.4 \quad(23.4)$ (1-167) months and the mean lifetime corticosteroid dose $4.8(6.9)(1-45)$ g. Table IV shows the bone mineral density values of the patients with different lifetime corticosteroid doses. The total lifetime corticosteroid dose had a significant correlation with bone mineral density in the lumbar spine $(r=-0 \cdot 164$, $\mathrm{p}=0.04)$, in the femoral neck $(r=-0.185$, $\mathrm{p}=0.02)$, in Ward's triangle $(r=-0.167$, $\mathrm{p}=0.04)$ and in the trochanter $(r=-0.237$, $\mathrm{p}=0.003)$. The mean time that had passed since the first corticosteroid dose was $9 \cdot 1(5 \cdot 7)$ (1-32) years. This time had a significant correlation with bone mineral density in the lumbar spine $(r=0.214, \mathrm{p}=0.023)$, but not elsewhere. There was a significant negative correlation between the duration of corticosteroid treatment and bone mineral density in the trochanter $(r=-0.215, p=0.013)$, but not in the other areas.

During the year preceding the study, eight of 152 patients $(5.3 \%)$ had received more than $2 \mathrm{~g}$ of prednisone/prednisolone. Their bone mineral density values were significantly lower than those of the other patients. The mean difference in the lumbar spine was $0.153 \mathrm{~g} / \mathrm{cm}^{2}$ ( $95 \%$ confidence limits for the mean difference (CL) 0.275 to $0.031, \mathrm{p}=0.015$ ), in the femoral neck $0.132 \mathrm{~g} / \mathrm{cm}^{2}$ (CL 0.233 to 0.031 , $\mathrm{p}=0.010$ ), in Ward's triangle $0.153 \mathrm{~g} / \mathrm{cm}^{2}(\mathrm{CL}$ 0.265 to $0.040, p=0.008)$, and in the trochanter $0.116 \mathrm{~g} / \mathrm{cm}^{2}$ (CL 0.217 to 0.015 , $\mathrm{p}=0.024$ ).

Eight of 152 patients (5.3\%) and two of 73 controls $(2 \cdot 7 \%)$ had $\mathrm{Z}$ scores in the spine lower than -2 SD. The total lifetime corticosteroid dose of these eight patients with low spinal bone mineral density values was $10 \cdot 1(12 \cdot 8)$ $(0-32) \mathrm{g}$ and the duration of their peroral corticosteroid treatment was $31.5(40.0)(0-108)$ months. One patient of eight had never received peroral corticosteroids. During the 12 months preceding the clinical examination, three of eight had not been using corticosteroids. Three of eight (37.5\%) had ileitis and another three had had fractures. Two patients had extraintestinal manifestations (one had liver disease), one had had an ileocaecal resection, and two had received immunosuppressive treatment.

\section{Discussion}

This study is the first to provide controlled data on bone mineral density in a large unselected group of IBD patients. The results show the association between a high lifetime corticosteroid dose and the low bone mineral density in these patients.

In this study, we used a local IBD register including all IBD patients treated in the hospital since 1986. Because of the follow up programme of these patients, even those with an IBD diagnosis made before 1986 were included. As our clinic is the only gastroenterology clinic in northern Finland, in an area with a population of roughly 300000 , the patients with IBD from this area are usually referred to us for colonoscopies and gastroenterological consultation. At the end of the year 1992, the register consisted of 519

TABLE IV Bone mineral densities (BMD, $\mathrm{g} / \mathrm{cm}^{2}$ ) in relation to the lifetime corticosteroid dose ( $\mathrm{g}$ of prednisone) prednisolone)

\begin{tabular}{|c|c|c|c|c|c|}
\hline & $\begin{array}{l}\text { Controls } \\
(n=73)\end{array}$ & $\begin{array}{l}\text { Group } 1^{\star} \\
(n=42)\end{array}$ & $\begin{array}{l}\text { Group } 2^{\star} \\
(n=66)\end{array}$ & $\begin{array}{l}\text { Group } 3^{\star} \\
(n=26)\end{array}$ & $\begin{array}{l}\text { Group } 4^{\star} \\
(n=18)\end{array}$ \\
\hline $\begin{array}{l}\text { Lifetime corticosteroid dose (g) } \\
\text { BMD }\end{array}$ & 0 & 0 & $1-5$ & $6-10$ & $>10$ \\
\hline $\begin{array}{l}\text { Lumbar spine } \\
\text { Femoral neck } \\
\text { Ward's triangle } \\
\text { Trochanter }\end{array}$ & $\begin{array}{l}1 \cdot 228(0 \cdot 156) \\
1 \cdot 001(0 \cdot 139) \\
0 \cdot 889(0 \cdot 162) \\
0 \cdot 888(0 \cdot 126)\end{array}$ & $\begin{array}{l}1.208(0 \cdot 175) \\
0.982(0 \cdot 130) \\
0.883(0 \cdot 136) \\
0.882(0 \cdot 132)\end{array}$ & $\begin{array}{l}1 \cdot 191(0.164) \\
0.960(0.134) \\
0.865(0 \cdot 150) \\
0.851(0 \cdot 131)\end{array}$ & $\begin{array}{l}1.156(0 \cdot 185) \\
0.925(0 \cdot 178) \\
0.825(0 \cdot 207) \\
0.793(0 \cdot 177) \ddagger\end{array}$ & $\begin{array}{l}1.085(0.163) \dagger \\
0.856(0.114) \dagger \\
0.758(0.135) \dagger \\
0.757(0.107) \dagger\end{array}$ \\
\hline
\end{tabular}

$\star 152$ patients with inflammatory bowel disease were divided into groups 1-4 on the basis of their lifetime corticosteroid dose. $t \mathrm{p}<0.05$ compared with the controls and the groups 1 and 2 (analysis of variance followed by the Student-Newman-Keuls test). $\neq \mathrm{p}<0.05$ compared with the controls and group 1 (analysis of variance followed by the Student-Newman-Keuls test). Data presented as mean (SD). 
ulcerative colitis patients and 150 patients with Crohn's disease. The prevalence of IBD calculated from these figures is practically the same as published previously in Scandinavia $^{16-19}$ and is in accordance with the data available on the reimbursement for the treatment of the Finnish IBD patients. ${ }^{20}$ We therefore believe that nearly all IBD patients in the area have been entered in the register.

The patients with IBD confined to the rectum only were excluded from our study, because usually only local symptoms are related to the rectal disease and this type of IBD has little effect on the nutritional status. Furthermore, peroral corticosteroids are seldom used in the IBD patients with proctitis. The same exclusion criteria has previously been used in a similar study. ${ }^{2}$ After the IBD diagnosis had been confirmed, a minimum of three years of follow up was required to ensure a correct diagnosis.

Two cross sectional studies have been published with the goal of clarifying the prevalence of low bone mineral density in the femoral and spinal areas in IBD patients. ${ }^{12}$ Pigot et $a l^{2}$ were the only ones to use dual energy $x$ ray absorptiometry. With dual energy $x$ ray absorptiometry-type densitometry, it is possible to achieve a good precision and a minimal radiation exposure in measuring bone mineral density at clinically relevant sites, such as the femoral neck and the spine. ${ }^{21}$ Computed tomography is also an accurate method in measuring bone mineral density in these sites, but it has the disadvantage of a considerably higher radiation exposure. Bone mineral density measurements of the spine and the femur are considered to be better predictors for fracture risk in these areas than peripheral densitometry. ${ }^{22} 23$ Each SD decrease in the femoral neck bone mineral density has been reported to increase the age adjusted risk for hip fracture $2 \cdot 6$-fold. ${ }^{23}$ As even a single bone mineral density measurement predicts hip fractures, ${ }^{23} 24$ a cross sectional study may show an increased fracture risk.

Pigot $e t a l^{2}$ found $23 \%$ of 61 IBD patients to have bone mineral density more than 2 SD below the previously established age and sex adjusted normal values at the spine and femoral levels. Compston et al ${ }^{1}$ measured the bone mineral density of 75 IBD patients with single photon absorptiometry from the radius and the bone mineral content with quantitative computed tomography from the spine. Twelve of 75 patients $(16 \%)$ had spinal trabecular bone mineral contents more than 2 SD below the previously published age and sex matched control value. In this study, only eight $(5.3 \%)$ patients at the spinal level and nine $(5.9 \%)$ at the femoral level had bone mineral density more than 2 SD below the age and sex adjusted reference value. In all of these three studies only adult patients over 18 years of age were included. In Pigot's study ${ }^{2}$ patients up to 70 years were included, but the mean age was even lower than in this study. In the study by Compston et al ${ }^{1}$ the oldest patient was 81 years old, but the mean age was very similar to this study. The bone mineral density of the elderly were not separately analysed. The inclusion of some older patients in the previous studies probably does not account for the differences between the $\mathrm{Z}$ scores of these studies and our study.

The previous studies included consecutive patients attending a gastroenterology clinic. According to Compston et $a l^{1}{ }^{1} 38$ of 51 (74.5\%) patients with Crohn's disease had undergone one or more intestinal resections. In Pigot's study, ${ }^{2} 13$ of 34 ulcerative colitis patients $(38 \cdot 2 \%)$ had an ileoanal anastomosis. In this study, only $17(21.8 \%)$ of 78 Crohn's disease patients had undergone small bowel resection and seven of 67 patients with ulcerative colitis $(10.4 \%)$ had undergone colectomy. The different treatment strategies may explain some of these differences, but it is probable that more difficult cases of IBD were included in the previous studies. This may be the reason for the reported lower bone mineral density values in IBD patients. Because of the controlled study design and the special effort made to achieve uniform and accurate diagnostic criteria for IBD we believe that this study characterises fairly well the bone mineral density of adult IBD patients.

Compston et al ${ }^{1}$ reported severe clinical osteoporosis with vertebral fractures only in the IBD patients who had been receiving high dose corticosteroid treatment (lifetime dose 15-65 g). They also found a significant negative correlation between bone mineral density and the lifetime corticosteroid dose. In accordance with their findings, we found low bone mineral density values in IBD to be closely related to the total lifetime corticosteroid dose. In this study, IBD patients who had never received peroral corticosteroids had virtually the same bone mineral density values as the controls. A study on patients with giant cell arteritis showed no additional osteoporosis related to corticosteroid use. ${ }^{25}$ The results were similar among patients with rheumatoid arthritis receiving corticosteroid treatment in doses (mean $8.0(0.5) \mathrm{mg} /$ day for a mean period of $89.6(12.0)$ months) resulting in considerably higher mean lifetime corticosteroid doses (over $20 \mathrm{~g}$ ) than in this study. ${ }^{26}$ These results might be taken to imply that other factors apart from the corticosteroids, such as disease activity, could be involved. The corticosteroid regimen prescribed to IBD patients in our hospital, however, which has mostly consisted of higher initial doses of 30-40 mg of prednisone or prednisolone/day and a slow tailing off of the dose over the course of several weeks, may have a more harmful effect on bone than the low dose maintenance treatment used in rheumatoid arthritis. High corticosteroid doses are so closely related to greater disease activity that it is impossible on the basis of this study to answer the question: 'How much of the osteoporosis is caused by corticosteroid treatment and what role has disease activity alone?' In the future, studies on patients receiving immunosuppressive treatment might shed light on this.

The deficiency of calcium and vitamin D absorption is well established in some patients 
with IBD. ${ }^{27-30}$ In this study, however, low bone mineral density values were not significantly related to either ileitis or small bowel resections. Similar results have been previously reported by Hylander et al. ${ }^{31}$ In this study, the effect of extensive small bowel resections on bone mineral density values could not be analysed, because none of the patients had had a small bowel resection of over $100 \mathrm{~cm}$. As menstrual abnormalities and reduced fertility are related to $\mathrm{IBD}^{32}$ sex hormone deficiency may be one of the pathogenetic factors in osteopenia of IBD patients. In contrast with Compston et $a l,{ }^{1}$ however, we were unable to find low bone mineral density values in amenorrhoeic women with IBD.

So far, two uncontrolled longitudinal studies of bone loss in IBD patients ${ }^{45}$ have been published. Controlled longitudinal studies including even the milder forms of IBD are still needed to confirm the rate of bone loss in these patients. Further studies of the bone loss in the adolescent and the elderly IBD patients are also needed. We conclude that IBD patients have significantly lower bone mineral density values than healthy controls, but according to our findings low bone mineral density values in these patients seem to be less common than has been reported previously. ${ }^{1231}$ In this study, the low bone mineral density in IBD patients was not related to the type or extent of the disease or to the duration of the illness. Low bone mineral density values were found in IBD patients with high lifetime corticosteroid doses, and especially the patients who have received over $5 \mathrm{~g}$ of prednisone/prednisolone should be monitored because of the possibly increased fracture risk. The IBD patients who had never received peroral corticosteroids did not have decreased bone mineral density values.

This work has been financially supported by the Finnish Foundation for Gastroenterology Research. We are grateful to the personnel of the Finnish State Railways Health Service for their assistance in the studies of the control group.

1 Compston JE, Judd D, Crawley EO, Evans WD, Evans C, Church HA, et al. Osteoporosis in patients with inflammatory bowel disease. Gut 1987; 28: 410-5.

2 Pigot F, Roux C, Chaussade S, Hardelin D, Pelleter O, Du Puy Montbrum T, et al. Low bone mineral density in patients with inflammatory bowel disease. Dig Dis $S_{c i}$ 1992; 9: 1396-403.

3 Bartley JJ. Crohn's disease: history and case report of associated metatarsal stress fracture. $7 \mathrm{Am}$ Podiatr Med Assoc 1989; 79: 82-3.

4 Motley RJ, Crawley EO, Evans C, Rhodes J, Compston JE. Increased rate of spinal trabecular bone loss in patients Increased rate of spinal trabecular bone loss in patients
with inflammatory bowel disease. Gut 1988; 29: 1332-6.

5 Clements D, Motley RJ, Evans WD, Harries AD, Rhodes J, Coles RJ, et al. Longitudinal study of cortical bone loss in patients with inflammatory bowel disease. Scand $f$ Gastroenterol 1992; 27: 1055-60.

6 Teufel M, Meyer-Hohnloser H, Morcke EM, Stubig U, Niessen KH. Nachuntersuchungen bei 60 kindern mi colitis ulcerosa und morbus Crohn. Monatsschr Kinderheilkd 1988; 136: 378-83.
7 Hahn TJ, Boisseau VC, Avioli LV. Effect of chronic corticosteroid administration on diaphyseal and metafyseal bone mass. $\mathcal{F}$ Clin Endocrinol Metab 1974; 39: 274-82.

8 Sitrin M, Meredith S, Rosenberg IH. Vitamin D deficiency and bone disease in gastrointestinal disorders. Arch Intern and bone disease in gast

9 Sitrin MD, Rosenberg IH, Chawla K, Meredith S, Sellin J, Rabb JM, et al. Nutritional and metabolic complications in a patient with Crohn's disease and ileal resection. Gastroenterology 1980; 78: 1069-79.

10 Vogelsang H, Ferenci P, Woloszczuk W, Resch H, Herold C, Frotz S, et al. Bone disease in vitamin D-deficient patients with Crohn's disease. Dig Dis Sci 1989; 34: 1094-9.

11 Binder V, Hendriksen C, Kreiner S. Prognosis in Crohn's disease - based on results from a regional patient group from the country of Copenhagen. Gut 1985; 26: 146-50.

12 Chong SKF, Blackshaw AJ, Boyle S, Williams CB, WalkerSmith JA. Histological diagnosis of chronic inflammatory bowel disease in childhood. Gut 1985; 26: 55-9.

13 Pera A, Bellando P, Caldera D, Ponti V, Astegiano M Barletti C, et al. Colonoscopy in inflammatory bowel disease: diagnostic accuracy and proposal of an endoscopic score. Gastroenterology 1987; 92: 181-5.

14 Kröger $\mathrm{H}$, Laitinen $\mathrm{K}$. Bone mineral density measured by dual-energy $\mathrm{X}$-ray absorptiometry in normal men. Eur 7 Clin Invest 1992; 22: 454-60.

15 Kröger H, Heikkinen J, Laitinen K, Kotaniemi A. Dualenergy X-ray absorptiometry in normal women: a crosssectional study of 717 Finnish volunteers. Osteoporos Int 1992; 2: 135-40.

16 Karvonen A-L, Tunturi-Hihnala H, Krekelä I. The prevalence and incidence of inflammatory bowel disease in the region of Tampere University Hospital [Abstract]. Scand region of Tampere University Hospital

17 Myren J, Gjone E, Hertzberg JN. Epidemiology of ulcerative colitis and regional enterocolitis (Crohn's disease) in Norway. Scand $f$ Gastroenterol 1971; 6: 511-4.

18 Binder V, Both H, Hansen PK, Hendriksen C, Kreiner S, Torp-Pedersen $\mathbf{K}$. Incidence and prevalence of ulcerative colitis and Crohn's disease in the country of Copenhagen 1962-1978. Gastroenterology 1982; 83: 563-8.

19 Lindberg E, Järnerot G. The incidence of Crohn's disease is not decreasing in Sweden. Scand $\mathcal{F}$ Gastroenterol 1991; 26: 495-500.

20 Finnish national agency for medicines. Finnish statistics on medicines 1992. The Social insurance institution of Finland, Helsinki: 1993.

21 Mazess RB, Barden HS. Measurement of bone by due photon absorptiometry (DPA) and dual-energy x-ray
absorptiometry (DEXA). Ann Chir Gynaecol 1988; 77: absorptiom.

22 Mazess RB. Bone density in diagnosis of osteoporosis: thresholds and breakpoints. Calcif Tissue Int 1987; 41: 117-8.

23 Cummings SR, Black DM, Nevitt MC, Browner W, Cauley $\mathrm{J}$, Ensrud $\mathrm{K}$, et al. Bone density at various sites for prediction of hip fractures. Lancet 1993; 341: 72-5.

24 Hui SL, Slemenda CW, Johnston CC. Baseline measurements of bone mass predicts fracture in white women. Ann Intern Med 1989; 111: 355-61.

25 Andersson R, Rundgren $\AA$, Rosengren K, Bengtsson B- $\AA$ Malmvall B-E, Mellström D. Osteoporosis after longterm corticosteroid treatment of giant cell arteritis. term corticosteroid treatment

26 Sambrook PN, Eisman JA, Yeates MG, Pocock NA, Eberl S, Champion GD, Osteoporosis in rheumatoid arthritis: safety of low dose corticosteroid. Ann Rheum Dis 1986 45: $950-3$.

27 Hylander E, Ladefoged K, Jarnum S. The importance of the colon in calcium absorption following small intestinal resection. Scand $\mathcal{F}$ Gastroenterol 1980; 15: 55-60.

28 Compston J, Craemer B. Plasma levels and intestina absorption of 25-hydroxyvitamin D in patients with small bowel resection. Gut 1977; 18: 171-5.

29 Driscoll R, Meredith S, Wagonfeld J, Rosenberg I. Bone histology and vitamin D status in Crohn's disease (CD): assessment of vitamin D therapy. Gastroenterology 1977; 72: 1051 .

30 Harries AD, Brown R, Heatley RV, Williams LA Woodhead JS, Rhodes J. Vitamin D status in Crohn's disease: association with nutrition and disease activity. disease: association with

31 Hylander E, Ladefoged K, Madsen S. Calcium balance and bone mineral content following small intestinal resection Scand $\mathcal{F}$ Gastroenterol 1981; 16: 167-76.

32 Farthing MJG, Dawson AM. Impaired semen quality in Crohn's disease - drugs, ill health, or undernutrition? Scand $\mathcal{f}$ Gastroenterol 1983; 18: 57-60. 